\title{
ANALISIS KINERJA PEMASOK BAHAN BAKU UTAMA PAKAN TERNAK (Kasus di Perusahaan Agroindustri Pakan Ternak PT. Japfa Comfeed Indonesia unit Gedangan, Sidoarjo, Jawa Timur) THE SUPPLIER PERFORMANCE ANALYSIS OF FEED MAIN RAW MATERIAL (Case at Agroindustrial Feed Company PT. Japfa Comfeed Indonesia Gedangan unit, Sidoarjo, East Java)
}

\author{
Rosalina Nisa Aminata ${ }^{1 *}$, Abdul Wahib Muhaimin ${ }^{2}$, Dina Novia Priminingtyas ${ }^{1}$ \\ Jurusan Sosial Ekonomi, Fakultas Pertanian, Universitas Brawijaya, Jl. Veteran 65145 Malang, \\ Indonesia
}

Received: 18th November 2015; Revised: 24th November 2015; Accepted: 25th November 2015

\begin{abstract}
ABSTRAK
Penelitian ini penting untuk dilakukan karena menurunnya komitmen beberapa pemasok jagung yang tidak mampu memenuhi syarat perusahaan dalam memenuhi permintaan jagung, sedangkan stabilitas produksi harus tetap dijaga oleh perusahaan. Banyaknya pemasok jagung yang bekerja sama dengan perusahaan menyebabkan kurangnya kontrol perusahaan terhadap kinerja pemasok, sehingga pesanan perusahaan yang dikirim oleh pemasok jagung tidak sesuai dengan kebutuhan perusahaan. Tujuan dari penelitian ini yaitu 1) Mengidentifikasi kriteria penilaian yang digunakan perusahaan untuk menilai kinerja pemasok 2) Mengidentifikasi urutan kriteria yang menjadi prioritas kinerja pemasok jagung 3) Menganalisis pemasok jagung yang menjadi prioritas utama dan yang patut dipertahankan dalam menjalin kerjasama. Metode penentuan sampel yang digunakan adalah snowball sampling untuk pemilihan sampel pemasok, dengan teknik pengumpulan data melalui wawancara terstruktur, kuesioner tertutup, dan dokumentasi berupa laporan bulanan dan tahunan. Fuzzy AHP sebagai metode analisis data, dilakukan dengan mengkalkulasi hasil skala perbandingan berpasangan yang telah dinilai oleh para informan, kemudian menghitung nilai vektor dan nilai defuzzifikasi, serta menormalisasikan angka fuzzy untuk mendapatkan bobot global dari masing-masing pemasok. Hasil dari Penelitian ini adalah kriteria yang digunakan dalam menilai kinerja pemasok yaitu kualitas, kuantitas, dan pengiriman. Pemasok jagung yang memiliki kinerja terbaik adalah pemasok N, sedangkan pemasok dengan bobot terendah adalah L. Kesimpulannya adalah perusahaan dapat mempertahankan pemasok $\mathrm{N}$ serta harus memperhatikan dan memberikan kontrol lebih kepada pemasok L agar kinerja yang diberikan menjadi lebih baik.
\end{abstract}

Kata kunci: Kinerja pemasok; performance; perbandingan berpasangan; fuzzy AHP

\section{ABSTRACT}

This research important because of the declining commitment some corn suppliers which is can't to cover company requirements set in occupy the demand of corn, while the production stability must be maintained by the company. Many of corn suppliers who work with the company involve lack control of the company about the performance of suppliers, so the company order which sent by corn suppliers don't comply the company's requirements. Goal of this research are 1) Identify the assessment criteria which is used the company to judge the performance of the supplier 2) Identify the sequence of criteria as priority corn supplier performance 3) Analyze corn supplier as main priority and which is should be maintained in cooperation. The sampling method which used is snowball sampling to election the supplier sampel, with data collection through structured interviews, closed questionnaires, and documentation of monthly and annual reports. Fuzzy AHP as analysis method, performed by calculating pairwise comparison scale results that have been assessed by the informants, calculate the value of the vector and defuzzification value, as well as normalize the fuzzy numbers to get the global weight of each supplier. The result from this research was the criteria used in evaluating the performance of suppliers is quality, quantity, and delivery. Corn suppliers that have the best performance is the supplier $N$, while the supplier with the lowest weight is $L$. Conclusion is not only company can maintain the supplier $N$ but also must pay attention and give more control to suppliers $L$ in order to performance be better.

Keywords: Supplier performance; performance; pairwise comparison; fuzzy AHP 


\section{Pendahuluan}

Ketersediaan sumber daya alam dan sumber daya manusia yang melimpah di Indonesia, sangat mungkin untuk mengembangkan kegiatan agribisnis dan agroindustri di Indonesia. Kegiatan agroindustri menurut Mangunwidjaja dan Sailah (2009) merupakan bagian dari kompleks industri pertanian sejak produksi bahan pertanian primer, industri pengolahan atau transformasi sampai produk dapat digunakan oleh konsumen. Komoditas agribisnis yang ketersediaannya melimpah dan produksinya terus meningkat dalam beberapa tahun terkahir adalah komoditas jagung (BPS, 2015).

Jagung sebagai salah satu komoditas pangan yang juga menjadi komponen utama dalam industri pembuatan pakan ternak merupakan bahan pakan berbutir yang penting dan banyak dipergunakan dalam menyusun ransum pakan. Jagung memiliki nilai gizi yang cukup tinggi, selain itu juga banyak mengandung karbohidrat yang baik sebagai sumber energi. Menurut Djanah (1985) dalam Kushartono (2000), jagung yang berwarna gelap selain mengandung vitamin $\mathrm{B}$, juga mengandung karotin. Penggunaan jagung dalam ransum pakan ayam bisa diberikan 20-40\%, sehingga ketersediaan jagung dalam industri pakan ternak harus terpenuhi.

Industri pakan ternak nasional tahun 2014 tumbuh $10 \%$ yang ditandai dengan meningkatnya konsumsi pakan sebesar 14,7 juta ton. Khusus kontribusi dari bahan baku jagung untuk pakan unggas tahun 2014 akan meningkat 7 juta ton, dari tahun 2013 sebesar 6,5 juta ton (Dinas Komunikasi dan Informatika, 2013). Kebutuhan pakan ternak terus mengalami peningkatan setiap tahunnya yang ditandai dengan meningkatnya produksi ternak. Menurut data GPMT (Gabungan Perusahaan Makanan Ternak) (2015), konsumsi pakan ternak terus meningkat. Pada tahun 2013 konsumsi pakan ternak mencapai 13,8 juta ton, dan pada tahun 2014 konsumsi pakan ternak mencapai 14,9 juta ton. Diperkirakan dalam periode tahun 2015 konsumsi pakan ternak mencapai 16,4 juta ton. Kenaikan konsumsi pakan ternak didorong oleh bertambahnya kapasitas produksi dan meningkatnya jumlah konsumsi akan ternak. Sehingga perusahaan

\footnotetext{
${ }^{*}$ Penulis Korespondensi.

E-mail: alin.aminata@gmail.com
}

harus mampu memenuhi permintaan konsumen seiring meningkatnya jumlah permintaan di pasar. Pada pernyataan sebelumnya, dapat diketahui bahwa kebutuhan akan pakan ternak semakin meningkat. Hal ini dirasakan oleh produsen pakan ternak, salah satunya adalah PT. Japfa Comfeed Indonesia. PT. Japfa Comfeed Indonesia (PT. JCI) merupakan salah satu perusahaan pakan ternak dengan tingkat produksi tinggi. Pada 2014, Perseroan berhasil meningkatkan produksi pakan sebesar $6,1 \%$ menjadi 2,8 juta ton (data annual report Japfa, 2014).

Tingginya jumlah produksi dan meningkatnya permintaan akan pakan ternak menyebabkan PT. JCI unit Gedangan memiliki banyak pemasok jagung. Permasalahan yang akan timbul dari banyaknya jumlah pemasok yang terdapat di PT. JCI adalah dapat menurunkan komitmen pemasok kepada perusahaan. Selain itu, kurangnya transparansi informasi yang diberikan oleh perusahaan dapat menurunkan komitmen dari pemasok jagung di PT. JCI unit Gedangan. Menurut Wibisono (2011) pada kebanyakan perusahaan, banyaknya jumlah pemasok merupakan suatu ukuran yang penting bagi perkembangan memperoleh material, namun perlu dilakukan pengurangan jumlah pemasok yang dapat meningkatkan kegiatan pengawasan, yang pada gilirannya dapat menjaga pasokan produk serta layanan ke perusahaan.

PT. JCI unit Gedangan sebenarnya sudah melakukan penilaian terhadap pemasoknya secara keseluruhan dengan menggunakan persentase berdasarkan pendapat evaluator saja. Selain itu PT. JCI tidak memiliki subkriteria pada setiap kriteria yang digunakan untuk menilai kinerja pemasok. Pada penelitian ini, evaluasi kinerja pemasok jagung di PT. JCI dilakukan dengan berdasarkan pada VPI (Vendor Performance Indicator) dengan standar yang telah ditetapkan PT. JCI. VPI merupakan istilah lain dari KPI (Key Performance Indicator) yang biasa diterapkan kepada penilaian pemasok (Indrajit dan Richardus, 2002). VPI yang digunakan dihitung bobotnya menggunakan metode Fuzzy AHP. Bobot alternatif pemasok juga dihitung menggunakan metode Fuzzy AHP.

Berdasarkan uraian di atas, maka melakukan penelitian analisis kinerja pemasok bahan baku utama pakan ternak di PT. Japfa Comfeed Indonesia. Penelitian ini dirasa penting untuk dilakukan karena pengukuran kinerja pemasok merupakan hal utama yang perlu 
dilakukan untuk mengetahui apakah tujuan dari kerjasama telah tercapai sesuai dengan yang diinginkan perusahaan. Selain itu, tujuan lain untuk mengetahui tingkat prestasi kerja pemasok yaitu agar dilakukan perbaikan untuk menjalin kerjasama. Permasalahan di PT. JCI unit Gedangan yaitu "menurunnya komitmen kinerja pemasok jagung dalam memenuhi permintaan perusahaan". Untuk menjawab pertanyaan tersebut, secara rinci disajikan dalam bentuk pertanyaan penelitian: 1) Apa saja kriteria penilaian yang digunakan perusahaan untuk menilai kinerja pemasok? 2) Bagaimana urutan kriteria yang menjadi prioritas kinerja pemasok jagung? 3) Manakah pemasok jagung yang menjadi prioritas utama dan yang patut dipertahankan dalam menjalin kerjasama?

Tujuan penelitian dirumuskan: 1) Mengidentifikasi kriteria penilaian yang digunakan perusahaan untuk menilai kinerja pemasok 2) Mengidentifikasi urutan kriteria yang menjadi prioritas kinerja pemasok jagung 3) Menganalisis pemasok jagung yang menjadi prioritas utama dan yang patut dipertahankan dalam menjalin kerjasama.

\section{Metode Penelitian}

Pemilihan lokasi dilakukan secara purposive yaitu di PT. Japfa Comfeed Indonesia, divisi pakan ternak unit Gedangan. Pemilihan lokasi penelitian ini dengan pertimbangan bahwa (1) perusahaan ini merupakan salah satu produsen pakan ternak besar di Indonesia yang salah satu tempat produksinya terdapat di Sidoarjo, (2) komoditi yang dipasok adalah jagung, karena jagung bahan baku utama dalam pembuatan pakan, dan (3) belum pernah dilakukan penelitian mengenai evaluasi kinerja pemasok jagung di PT. JCI unit Gedangan, Sidoarjo. Pemilihan responden dilakukan dengan cara purposive dengan pertimbangan responden adalah orang yang mewakili kepentingan pada proses dalam memasok bahan baku sesuai dengan kriteria yang ditetapkan, dan terdapat tiga orang yaitu kepala departemen procurement, staf procurement, serta bagian staf pergudangan. Metode penentuan pemasok jagung yang dinilai kinerjanya dilakukan secara purposive atas dasar bahwa jagung merupakan bahan baku utama dalam pembuatan pakan ternak, dan jagung merupakan salah satu komoditas yang banyak dibudidayakan di Indonesia. Pemilihan nama pemasok jagung dilakukan dengan snowball sampling, dimana data pemasok jagung yang masih bekerjasama didapatkan dari informan yaitu bagian procurement dan keseluruhan pemasok jagung berjumlah 14 pemasok yang aktif mengirimkan pada periode September 2013Agustus 2014. Teknik pengumpulan data dalam melaksanakan penelitian ini yaitu dengan wawancara terstruktur, kuesioner tertutup, dan dokumentasi berupa laporan bulanan dan tahunan. Metode analisis data yang digunakan untuk menjawab tujuan penelitian, 1) menyususn matriks perbandingan berpasangan dan dilakukan uji konsistensi tiap matriks, 2) mentransformasikan matriks perbandingan berpasangan ke dalam himpunan fuzzy, 3) Mencari nilai bobot vektor sebagai urutan prioritas dengan metode Fuzzy AHP dengan menggunakan Microsoft Excel.

Metode analisis data untuk masing-masing tujuan dalam penelitian sebagai berikut:

Tujuan 1: Menganalisis kriteria yang Digunakan PT. JCI unit Gedangan untuk Menilai Kinerja Pemasok. Analisis yang digunakan yaitu dengan menyusun matriks perbandingan berpasangan dari hasil kuesioner dari 22 kriteria hingga didapatkan tiga kriteria terpilih dan dilakukan uji konsistensi untuk masing-masing matriks.

Tujuan 2: Menganalisis urutan kriteria yang menjadi prioritas untuk digunakan dalam menilai kinerja pemasok. Analisis yang digunakan yaitu dengan menyusun matriks perbandingan berpasangan dari tiga kriteria terpilih, lalu dilakukan transformasi matriks perbandingan berpasangan ke dalam himpunan fuzzy dan mencari nilai bobot lokal masing-masing kriteria. Tujuan 3: Menganalisis pemasok jagung yang menjadi prioritas utama Analisis yang digunakan yaitu dengan menyusun matriks perbandingan berpasangan dari 14 pemasok jagung dilihat berdasarkan tiga kriteria yang digunakan. Kemudian matriks perbandingan berpasangan ditransformasikan ke dalam himpunan fuzzy, dan dicari nilai bobot vektor sebagai urutan prioritas dengan metode Fuzzy AHP. Menentukan konsistensi matriks:

$\mathrm{CI}=\frac{\lambda \text { maks }-\mathrm{n}}{n-1}$

Dimana,

$\mathrm{n}=$ jumlah ordo kriteria, subkriteria, dan alternatif pemasok yang digunakan.

$\mathrm{CI}=$ Consistency Indeks pengisian kuesioner oleh pakar.

$\lambda$ maksimum diperoleh dari nilai terbesar eigen bobot prioritas dari kriteria, subkriteria, dan alternatif pemasok. 
Suatu matriks perbandingan berpasangan dinyatakan konsisten apabila nilai CR $\leq 10 \%$. CR dapat dihitung menggunakan rumus sebagai berikut:

$\mathrm{CR}=\frac{\mathrm{CI}}{\mathrm{RI}}$

Keterangan :

$\mathrm{CI}=$ nilai consistency indeks pengisian kuesioner oleh pakar.

$\mathrm{RI}=$ nilai random index dari ordo kriteria, subkriteria, dan alternatif pemasok yang digunakan.
Fuzzy AHP menurut Chang (1996) adalah seperti berikut :

1) Membuat struktur hirarki masalah yang akan diselesaikan yang diawali dengan tujuan umum, dilanjutkan dengan kriteria, subkriteria, dan alternatif, dan menentukan perbandingan matriks berpasangan antar kriteria dan subkriteria dengan menggunakan skala Triangular Fuzzy Number (TFN) seperti pada Tabel 1.

Tabel 1. Perhitungan skala nilai TFN (Chang, 1996)

\begin{tabular}{clll}
$\begin{array}{c}\text { Intensitas } \\
\text { Kepentingan AHP }\end{array}$ & \multicolumn{1}{c}{ Himpunan Linguistik } & $\begin{array}{c}\text { Triangular Fuzzy } \\
\text { Number (TFN) }\end{array}$ & $\begin{array}{c}\text { Reciprocal } \\
\text { (kebalikan) }\end{array}$ \\
\hline 1 & $\begin{array}{l}\text { Perbandingan elemen yang sama } \\
\text { Equal) }\end{array}$ & $(1,1,1)$ & $(1,1,1)$ \\
2 & $\begin{array}{l}\text { Pertengahan (Intermediate) } \\
\text { Elemen satu cukup penting dari yang }\end{array}$ & $(1 / 2,1,3 / 2)$ & $(2 / 3,1,2)$ \\
3 & $\begin{array}{l}\text { lainnya (Moderately Important) } \\
\text { Pertengahan (Intermediate) }\end{array}$ & $(3 / 2,2,2,5 / 2)$ & $(2 / 5,1 / 2,2 / 3)$ \\
4 & $\begin{array}{l}\text { Elemen satu kuat pentingnya dari yang } \\
\text { lain (Strongly Important) }\end{array}$ & $(2,5 / 2,3)$ & $(1 / 3,2 / 5,1 / 2)$ \\
5 & $\begin{array}{l}\text { Pertengahan (Intermediate) } \\
\text { Elemen satu lebih kuat pentingnya dari } \\
\text { yang lain (Very Strong) }\end{array}$ & $(3,7 / 2,4)$ & $(2 / 7,1 / 3,2 / 5)$ \\
7 & $\begin{array}{l}\text { Pertengahan (Intermediate) } \\
\text { Elemen satu mutlak lebihpenting dari } \\
\text { yang lainnya (Extremely Strong) }\end{array}$ & $(4,9 / 2,4,9 / 2)$ & $(2 / 9,1 / 4,2 / 7)$ \\
9 & & & $(2 / 9,2 / 9,1 / 4)$ \\
\hline
\end{tabular}

Menentukan rata-rata geometrik dilakukan jika terdapat multi partisipan. Sehingga nilai perbandingan pada setiap partisipan dirata-rata terlebih dahulu. Untuk itu, Saaty menyarankan untuk menggunakan metode geometric mean dengan rumus,

$\mathrm{GM}=\sqrt[n]{\sum_{1=1}^{n} X_{I}}$

Dimana:

$\mathrm{GM}=$ Geometric mean dari tiga pakar partisipan

$\mathrm{X}_{\mathrm{i}}=$ Pakar ke-i (sesuai dengan pakar partisipan)

$\mathrm{n}=$ Jumlah pakar partisipan

2) Menentukan nilai sintetis fuzzy $\left(S_{i}\right)$ prioritas kriteria, subkriteria, dan alternatif pemasok dengan rumus,

$S_{i}=\sum_{j=1}^{m} M_{g i}^{j} \otimes\left[\sum_{i=1}^{n} \sum_{j=1}^{m} M_{g i}^{j}\right]^{-1}$

Dimana,

$\sum_{j=1}^{m} M_{g i}^{j}=\left(\sum_{j=1}^{m} l_{j}, \sum_{j=1}^{m} m_{j}, \sum_{j=1}^{m} u_{j}\right)$

$$
\begin{aligned}
& \sum_{i=1}^{n} \sum_{j=1}^{m} M_{g i}^{j}=\left(\sum_{i=1}^{n} l_{i}, \sum_{i=1}^{n} m_{i}, \sum_{i=1}^{n} u_{i}\right) \ldots \ldots \ldots .(5) \\
& {\left[\sum_{i=1}^{n} \sum_{j=1}^{m} M_{g i}^{j}\right]^{-1}=\left(\frac{1}{\sum_{i=1}^{n} u_{i}}, \frac{1}{\sum_{i=1}^{n} m_{i}}, \frac{1}{\sum_{i=1}^{n} l_{i}}\right)}
\end{aligned}
$$

Keterangan :

$S_{i}=$ nilai dari fuzzy syntetic extent, pada kriteria, subkriteria, atau alternatif ke-i.

$M_{g i}^{j}(j=1,2,3, \ldots \mathrm{m})$ : bilangan triangular fuzzy yang dimiliki oleh masing-masing kriteria, subkriteria, atau alternatif yang mempengaruhi objek ke-i.

$g i$ : kriteria, subkriteria, atau alternatif yang mempengaruhi objek ke-i.

$\sum_{j=1}^{m} M_{g i}^{j}$ : jumlah bilangan alternatif triangular fuzzy yang mempengaruhi kriteria, subkriteria, atau alternatif.

$\left[\sum_{i=1}^{n} \sum_{j=1}^{m} M_{g i}^{j}\right]^{-1}:$ invers dari total jumlah TFN (Triangular Fuzzy Number) yang mempengaruhi kriteria, subkriteria, atau alternatif pada semua objek. 
3) Menentukan nilai vektor (V) dan nilai defuzzifikasi (d')

Membandingkan $\mathrm{M}_{1}$ dan $\mathrm{M}_{2}$, maka dibutuhkan nilai dari $\mathrm{V}\left(\mathrm{M}_{1} \geq \mathrm{M}_{2}\right)$ dan $\mathrm{V}\left(\mathrm{M}_{2} \geq\right.$ $\left.\mathrm{M}_{1}\right)$. Tingkat kemungkinan dari $\mathrm{M}_{2}=\left(\mathrm{l}_{2}, \mathrm{~m}_{2}, \mathrm{u}_{2}\right)$ $\geq \mathrm{M}_{1}\left(\mathrm{l}_{1}, \mathrm{~m}_{1}, \mathrm{u}_{1}\right)$ didefinisikan sebagai $\mathrm{V}\left(\mathrm{M}_{2} \geq\right.$ $\left.\mathrm{M}_{1}\right)=\sup \left[\min \left(\mu_{\mathrm{M} 2}((\mathrm{x}),(\mathrm{y}))\right]\right.$ dan setara dengan:

$$
\begin{aligned}
\mathrm{V} & =\left(\mathrm{M}_{2} \geq \mathrm{M}_{1}\right)=\operatorname{hgt}\left(\mathrm{M}_{1} \cap \mathrm{M}_{2}\right) \\
& =\left\{\begin{array}{ll}
1, & \text { if } m_{2} \geq m_{1} \\
0, & \text { if } l_{1} \geq u_{2} \\
\frac{l_{1}-u_{2}}{\left(m_{2}-u_{2}\right)-\left(m_{1}-l_{1}\right)}, & \text { otherwise }
\end{array}\right\}
\end{aligned}
$$

4) Normalisasi nilai bobot vektor fuzzy $(W)$

Mencari nilai minimum dari tingkat kemungkinan sebuah bilangan convex fuzzy lebih besar dari bilangan $\mathrm{k}$ convex fuzzy $\mathrm{M}_{\mathrm{i}}(i=1,2,3$, ...k) dapat didefinisikan sebagai berikut

$\mathrm{V}\left(\mathrm{M} \geq \mathrm{M}_{1}, \mathrm{M}_{2}, \ldots, \mathrm{M}_{\mathrm{k}}\right)$

$=\mathrm{V}\left[\left(\mathrm{M} \geq \mathrm{M}_{1}\right)\right.$ dan $\left(\mathrm{M} \geq \mathrm{M}_{2}\right)$ dan $\left.\left(\mathrm{M} \geq \mathrm{M}_{\mathrm{k}}\right)\right]$

$=\min \mathrm{V}\left(\mathrm{M} \mathrm{M}_{i}\right), i=1,2,3, . ., \mathrm{k}$

Diasumsikan bahwa:

d' $\left(A_{i}\right)=\min V\left(S_{i} \geq S_{k}\right)$ untuk $k=1,2,3, . . n ; k \neq$

0

maka vektor bobot didefinisikan sebagai berikut:

$W^{\prime}=\left(d^{\prime}\left(A_{1}\right), d^{\prime}\left(A_{2}\right), \ldots, d^{\prime}\left(A_{n}\right)\right)^{T}$

Setelah dilakukan normalisasi dari persamaan (9) maka nilai bobot vektor yang dinormalisasikan adalah seperti rumus berikut:

$W^{\prime}=\left(d^{\prime}\left(A_{1}\right), d^{\prime}\left(A_{2}\right), \ldots, d^{\prime}\left(A_{n}\right)\right)^{T}$

menjadi

$\mathrm{W}=\left(\mathrm{d}\left(\mathrm{A}_{1}\right), \mathrm{d}\left(\mathrm{A}_{2}\right), . ., \mathrm{d}\left(\mathrm{A}_{\mathrm{n}}\right)\right)^{\mathrm{T}}$

dimana $\mathrm{W}$ bukan merupakan bilangan fuzzy.

Menentukan bobot akhir pemasok diperoleh dari jumlah perkalian antara bobot prioritas alternatif tiap pemasok dengan bobot kriteria. Adapun bobot prioritas alternatif tiap pemasok diperoleh dari jumlah perkalian antara bobot alternatif dengan bobot kriteria. Setelah didapatkan bobot akhir pemasok maka dilakukan peringkat kinerja pemasok. Perumusan normalisasinya adalah,

$d\left(A_{n}\right)=\frac{d^{\prime}(A n)}{\sum_{i=1}^{n} d^{\prime}(A n)}$

Normalisasi bobot ini akan dilakukan agar nilai dalam vektor diperbolehkan menjadi analog bobot dan terdiri dari bilangan yang non-fuzzy.

\section{Hasil Dan Pembahasan}

Hingga saat ini, industri perunggasan Indonesia merupakan salah satu penyumbang terbesar terhadap PDB dari sektor pertanian, selain kelapa sawit. Hal ini menunjukkan bahwa peran dan kontribusi industri perunggasan akan semakin signifikan dalam pertumbuhan ekonomi nasional. Salah satu industri perunggasan terbesar dan terintegritas adalah PT. Japfa Comfeed Indonesia. Tidak hanya terintegritas, PT. Japfa Comfeed Indonesia juga memiliki kontribusi besar dalam perekonomian nasional. Unit bisnis utama perusahaan ini yakni pembuatan pakan ternak, pembibitan ayam, pengolahan unggas serta pembudidayaan pertanian. Perusahaan ini tersebar di seluruh wilayah Indonesia (salah satunya terletak di Gedangan Sidoarjo), sehingga sudah dapat dipastikan mampu menyerap tenaga kerja dalam jumlah yang besar.

Kondisi tersebut memperlihatkan luasnya lapangan kerja yang dapat dimanfaatkan sejalan dengan berkembangnya industri. Menurut data statistik tahunan perusahaan, karyawan di PT. Japfa Comfeed Indonesia pada tahun 2014 mengalami peningkatan $14.7 \%$ dari tahun sebelumnya yang tercatat sejumlah 16.588 orang, hal ini juga disebabkan karena adanya ekspansi dan penambahan kapasitas produksi juga membutuhkan jumlah tenaga kerja baru. Tidak hanya tenaga kerja, dengan bertumbuhnya industri perunggasan juga berfungsi sebagai faktor penggerak industri pertanian terkait lainnya, seperti budidaya jagung.

\section{Penentuan Kriteria Kinerja Pemasok yang Digunakan}

Evaluasi kinerja pemasok menurut Pujawan (2005) sangat diperlukan terutama bila pemasok akan memasok dalam jangka panjang. Kriteria yang digunakan dalam pemilihan dan evaluasi harus mencerminkan strategi kegiatan persediaan dari item yang akan dipasok. Perlu dilakukan penyesuaian kriteria yang digunakan dalam melakukan evaluasi kinerja pemasok sesuai dengan karakteristik yang berkaitan dengan pemasokan biji jagung ke pabrikan, agar tidak ada ketimpangan pendapat antar evaluator.

Penentuan kriteria yang digunakan dalam menilai kinerja pemasok dilakukan setelah melakukan penyusunan struktur hierarki yang dalam penelitian ini terdapat empat tingkat. Tingkat pertama merupakan goal yang akan dicapai, tingkat selanjutnya adalah kriteria yang digunakan untuk menilai kinerja, berikutnya adalah subkriteria pada masing-masing kriteria, dan yang terakhir adalah pemasok alternatif yang kemudian akan dipilih menjadi pemasok yang diprioritaskan berdasarkan dengan kriteria yang digunakan untuk melakukan penilaian kinerja pemasok. Pada tingkat kedua, penetapan kriteria 
yang dapat dilakukan dengan studi literatur dan melalui wawancara dengan pakar/evaluator yang dianggap expert dibidangnya, terutama dalam Departemen Procurement, karena kegiatan pemilihan pemasok merupakan tugas dari Departemen Procurement (pembelian). Dalam melakukan evaluasi kinerja pemasok yang berkaitan dengan pasokan jagung di PT. JCI unit Gedangan sudah berdasarkan ISO 2008:9001 dan sesuai dengan SOP yang berlaku sejak tahun 2007. Kriteria yang sudah ditetapkan ini antara lain kriteria kualitas produk, kuantitas produk, dan pengiriman produk pada perusahaan, dimana prioritas dari kriteria terpilih tersebut akan menentukan pemasok mana yang memiliki prioritas utama dalam memasok jagung di PT. JCI unit Gedangan. Penentuan ketiga kriteria tersebut didasarkan adanya keterkaitan dan saling mempengaruhi antar kriteria-kriteria tersebut. Selain itu, penentuan kriteria juga didasarkan pada item yang dipasok oleh pemasok. Skema untuk AHP seperti pada Gambar 1.

Kriteria yang digunakan dalam menilai kinerja pemasok diantaranya kualitas, kuantitas, dan pengiriman. Kriteria ini merupakan hasil seleksi pengisian kuesioner dengan matriks perbandingan berpasangan dari 22 kriteria VPI dari penelitian Dickson. Pada kriteria kualitas, PT. JCI unit Gedangan menggunakan subkriteria sesuai dengan kriteria kualitas bahan baku yang dikirim, yakni kemampuan pemasok membatasi adanya aflatoxin 150 part per billion, kemampuan pemasok membatasi adanya jamur maksimal 4 persen dari total keseluruhan jagung yang dikirim, kesesuaian kadar air jagung maksimal 15 persen dari total keseluruhan jagung yang dikirim, kesesuaian aroma harus fresh, kemampuan pemasok membatasi biji pecah maksimal 5 persen dari total keseluruhan jagung yang dikirim, dan kemampuan pemasok membatasi biji mati maksimal 8 persen dari total keseluruhan jagung yang dikirim. Kriteria kuantitas dengan subkriteria pemasok harus memiliki cadangan pasokan yang berkelanjutan, dan tepat jumlah sesuai yang diminta saat bahan baku tiba di perusahaan. Kriteria pengiriman dengan subkriteria kondisi bahan baku yang aman dalam packaging selama perjalanan, cepat sampai di perusahaan, dan tepat sampai di perusahaan.

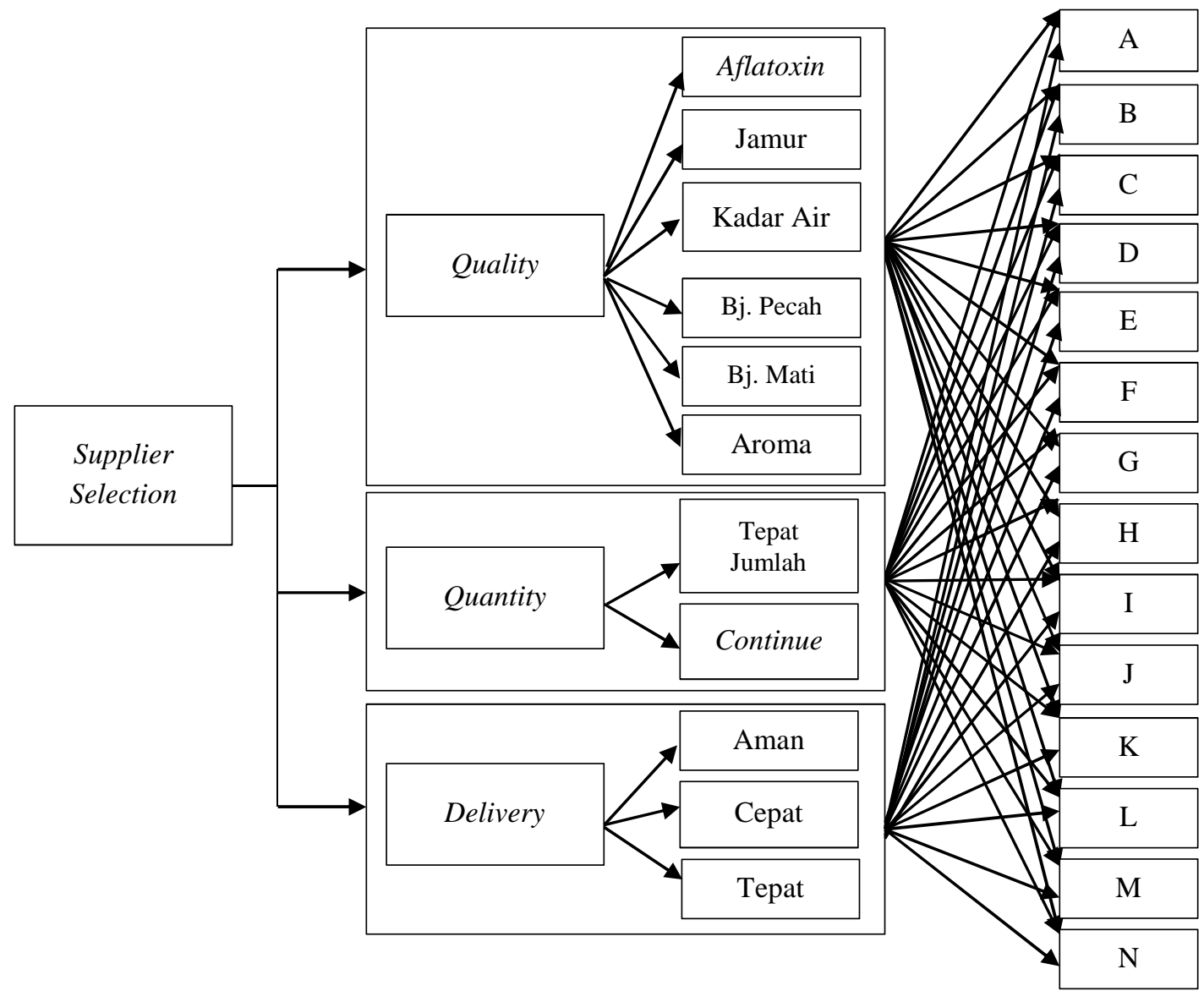

Gambar 1. Skema Model Hierarki Pengukuran Kinerja Pemasok di PT. Japfa Comfeed Indonesia unit Gedangan 
2. Menentukan Urutan Kriteria Kinerja

Perhitungan bobot prioritas untuk urutan kriteria dihitung dengan tahap awal yaitu mengkonsistensikan matriks perbandingan berpasangan. Dengan melakukan uji konsistensi ini akan diketahui apakah hasil kuesioner telah valid. Dari keseluruhan kriteria, perhitungan konsistensi menunjukkan nilai $<10 \%$, yang berarti pengisian kuesioner telah valid dilakukan oleh para pakar sebagai responden. Selanjutnya kriteria dilakukan perhitungan bobot dengan menggunakan metode fuzzy AHP. Kriteria yang paling menentukan dalam penilaian kinerja pemasok bahan baku jagung adalah kualitas dengan nilai 0.590. Urutan kriteria dari yang memiliki bobot tertinggi hingga terendah secara berurutan dalam evaluasi kinerja pemasok yakni (1) kualitas; (2) kuantitas; dan (3) pengiriman dengan bobot masing-masing adalah 0.590, 0.212 , dan 0.198. Dengan begitu kriteria kualitas merupakan kriteria yang dianggap paling diprioritaskan diantara kriteria yang lain.

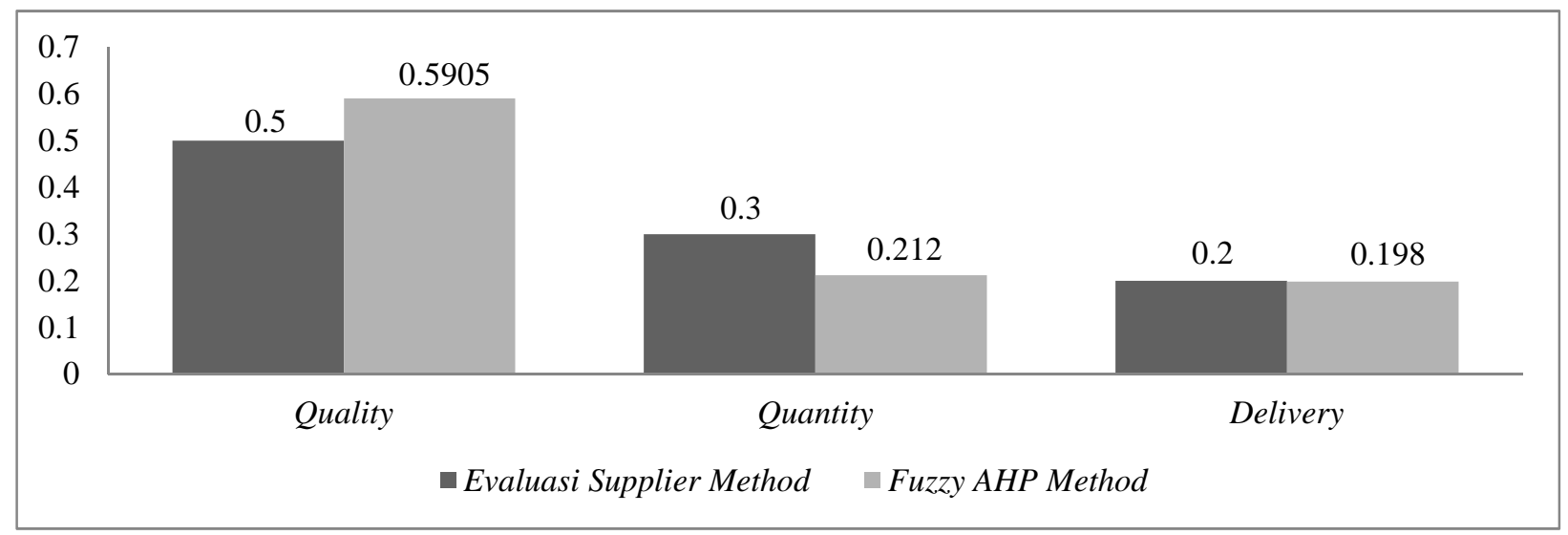

Gambar 2. Diagram Perbandingan Pembobotan Kriteria Utama menggunakan Metode Evaluasi Supplier dan Fuzzy AHP

3. Menentukan Pemasok alternatif Terbaik

Penentuan pemasok dengan alternatif terbaik dilakukan dengan cara seperti halnya pada penentuan urutan kriteria kinerja. Hasil perhitungan yang diperoleh pemasok terbaik yang bekerjasama dengan PT. Japfa Comfeed Indonesia unit Gedangan yakni dapat dilihat pada Gambar 3. berikut ini.

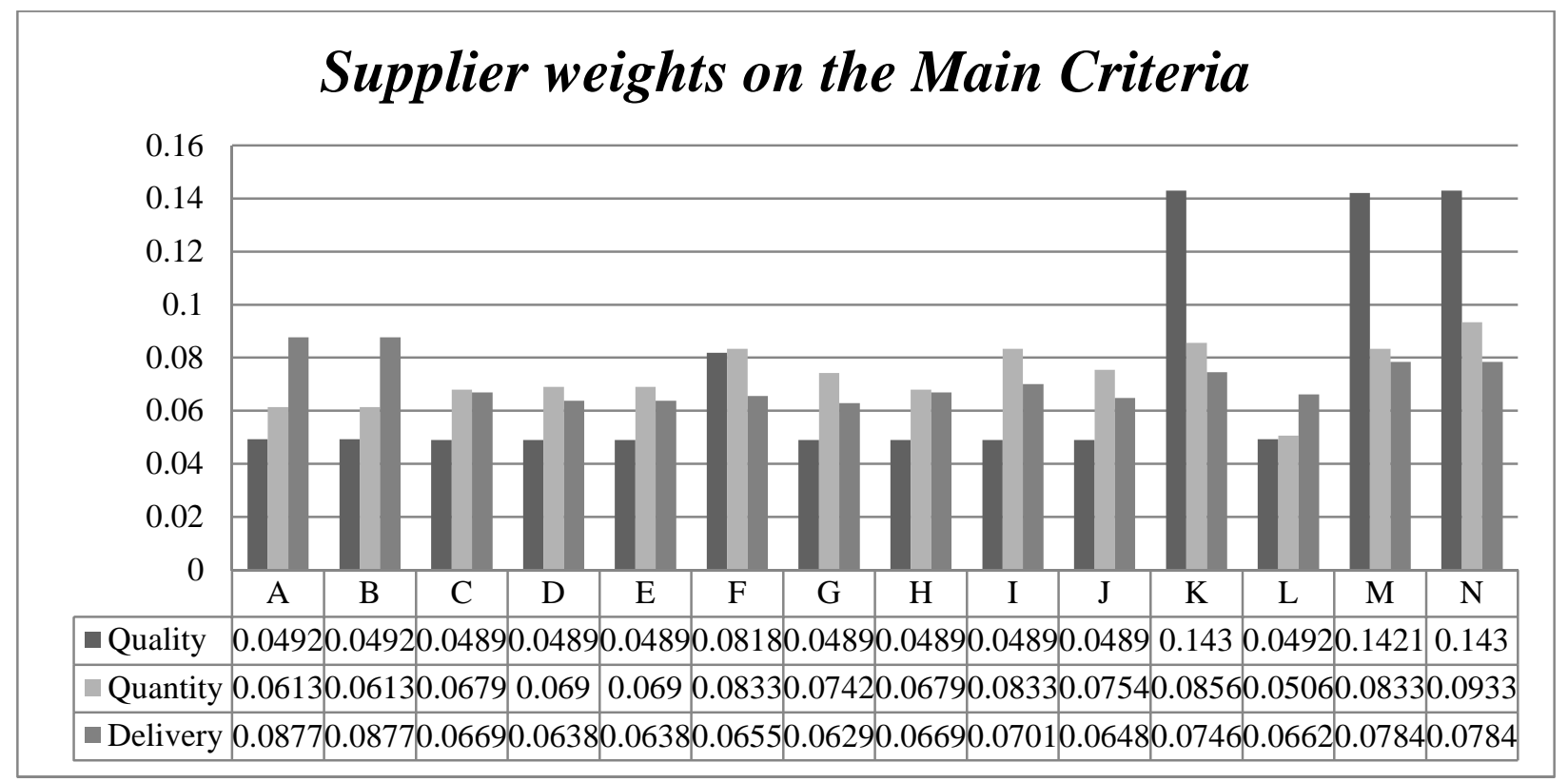

Gambar 3. Bobot Pemasok pada Kriteria Utama 
Dilihat dari penilaian bobot prioritas secara lokal adalah pemasok pada kriteria kualitas dengan bobot prioritas tertinggi adalah pemasok $\mathrm{K}$, dan yang terendah adalah pemasok A. Jika dilihat dari kriteria kuantitas, maka tingkat kinerja pemasok yang memiliki bobot tertinggi pemasok $\mathrm{N}$, dan yang terendah adalah pemasok E. Prioritas lokal pemasok dari kriteria pengiriman, maka pemasok dengan bobot prioritas tertinggi adalah pemasok A, dan yang terendah adalah pemasok $\mathrm{G}$.
Sedangkan penilaian bobot prioritas alternatif supplier secara global pada periode September 2013-Agustus 2014 pada unit Gedangan dengan nilai tertinggi adalah pemasok $\mathrm{N}$, dan alternatif supplier dengan nilai bobot global terendah adalah pemasok L. Akan tetapi, hasil penelitian ini hanya sebagai rekomendasi dalam mengambil suatu keputusan. Hasil perhitungan bobot global dapat dilihat pada Tabel 2. berikut ini.

Tabel 2. Ranking Pembobotan Kinerja Pemasok Jagung di JCI unit Gedangan

\begin{tabular}{lrrrrr}
\hline Supplier & \multicolumn{1}{c}{ Quality } & \multicolumn{1}{c}{ Quantity } & Delivery & Global Weight & \multicolumn{1}{c}{ Ranking } \\
\hline A & 0.0492 & 0.061 & 0.0877 & 0.059413 & 6 \\
B & 0.0492 & 0.061 & 0.0877 & 0.059413 & 7 \\
C & 0.0489 & 0.068 & 0.0669 & 0.056516 & 10 \\
D & 0.0489 & 0.069 & 0.0638 & 0.056136 & 12 \\
E & 0.0489 & 0.069 & 0.0638 & 0.056136 & 13 \\
F & 0.0818 & 0.083 & 0.0655 & 0.078932 & 4 \\
G & 0.0489 & 0.074 & 0.0629 & 0.05706 & 9 \\
H & 0.0489 & 0.068 & 0.0669 & 0.056516 & 11 \\
I & 0.0489 & 0.083 & 0.0701 & 0.060415 & 5 \\
J & 0.0489 & 0.075 & 0.0648 & 0.057691 & 8 \\
K & 0.143 & 0.086 & 0.0746 & 0.11736 & 2 \\
L & 0.0492 & 0.051 & 0.0662 & 0.052887 & 14 \\
M & 0.1421 & 0.083 & 0.0784 & 0.117093 & 3 \\
N & 0.143 & 0.093 & 0.0784 & 0.119744 & 1 \\
\hline
\end{tabular}

\section{Kesimpulan}

Kriteria-kriteria yang digunakan PT. JCI unit Gedangan untuk menilai kinerja pemasok jagung meliputi kriteria kualitas, kriteria kuantitas, dan kriteria pengiriman. Masingmasing kriteria terdapat subkriteria yang mendukung setiap kriteria-kriteria tersebut.

Urutan kriteria dari yang memiliki bobot tertinggi hingga terendah secara berurutan dalam evaluasi kinerja pemasok yakni (1) kualitas; (2) kuantitas; dan (3) pengiriman dengan bobot masing-masing adalah $0.590,0.212$, dan 0.198. Kriteria yang memiliki bobot tertinggi adalah kualitas dengan nilai 0.590, yang berarti kriteria kualitas dianggap sebagai kriteria yang diprioritaskan untuk menilai kinerja pemasok jika dibandingkan dengan dua kriteria lain yang memiliki bobot dibawah itu.

Penilaian bobot prioritas alternatif supplier secara global pada periode September 2013Agustus 2014 pada unit Gedangan dengan nilai tertinggi adalah pemasok $\mathrm{N}$, dan alternatif supplier dengan nilai bobot global terendah adalah pemasok $L$.
Sebaiknya PT. JCI unit Gedangan juga mempertimbangkan dan mengembangkan kriteria yang digunakan dalam menilai dan memilih pemasok jika dilihat masih ada beberapa pemasok jagung yang masih kurang cekatan dalam menanggapi jagung yang tidak sesuai dengan permintaan perusahaan. Salah satu kriteria yang dapat digunakan dan sebagai bahan pertimbangan adalah kriteria service yang diberikan oleh pemasok setelah barang sudah diterima oleh pihak perusahaan, dan kriteria informasi dari perusahaan ke pemasok, sehingga proses perbaikan kerjasama akan lebih efektif.

Perhitungan persentase dari FAHP ada baiknya untuk dijadikan sebagai bahan pertimbangan pada persentase kriteria di PT. JCI unit Gedangan, karena metode FAHP lebih detail untuk nilai bobot yang akan digunakan untuk menilai pemasok.

\section{Daftar Pustaka}

[1]. Annual Report Japfa. 2013. Japfa 2013 Annual Report. www.japfacomfeed.co.id, diakses pada Agustus 2014. 
[2]. BPS (Badan Pusat Statistik). 2015. Produksi Jagung Menurut Provinsi. www.bps.go.id, diakses pada Agustus 2015.

[3]. Chang. 1996. Application of The Extent Analysis Method on Fuzzy AHP. European Jurnal of Operational Research, 95,649655.

[4]. Dinas Komunikasi dan Informatika. 2013. Kebutuhan Pakan Ternak. http://kominfo.jatimprov.go.id, diakses pada Agustus 2014.

[5]. GPMT (Gabungan Perusahaan Makanan Ternak). 2015. Produktivitas Pakan Ternak. Tersedia di asosiasigpmt.blogspot.com, diakses pada Mei 2015.

[6]. Indrajit, R. E. dan Richardus, D. 2002. Konsep Manajemen Supply Chain; Cara baru memandang mata rantai penyediaan barang. Grsindo. Jakarta.

[7]. Kushartono, B. 2000. Penentuan Kualitas Bahan Baku Pakan dengan Cara Organoleptik. Temu Teknis Fungsional non Peneliti. Balai Penelitian Ternak. Pusat Penelitian dan Pengembangan Pertanian. Hal 217-223.

[8]. Mangunwidjaja dan Sailah. 2009. Pengantar Teknologi Pertanian. Penebar Swadaya. Bogor.

[9]. Pujawan. 2005. Supply Chain Management. Penerbit Guna Widya. Surabaya.

[10]. Saaty, T. L. 1990. How to Make a Decision: The Analytic Hierarchy Process, Europian Journal of Operation Research.

[11]. Wibisono, D. 2011. Manajemen Kinerja Korporasi dan Organisasi. Penerbit Erlangga. Jakarta. 